\title{
Measuring suction pressure via a scavenging system
}

\author{
Takahiro Tamura ${ }^{1}$
}

Received: 10 June 2019 / Accepted: 16 June 2019 / Published online: 24 June 2019

(c) Japanese Society of Anesthesiologists 2019

Keywords Suction pressure $\cdot$ Volatile anesthetic $\cdot$ Scavenging system

To the Editor:

An enhanced modified VA suction system to prevent VA leakage during cardiopulmonary bypass was recently reported [1]. The underlying idea is to use a scavenging system for volatile anesthetic. I report an experiment showing the basis of the suction pressure of volatile anesthetic using a scavenging system.

The scavenging system uses an injector type that uses compressed air to create a vacuum (CENTRAL UNI Co., Ltd., Tokyo, Japan). The supply pressure of compressed air to the injector is $0.3 \mathrm{MPa}$. The principle of negative pressure generation by the injector system is shown in Supplementary Fig. 1. Compressed air is squeezed by the nozzle, and flows into the diffuser. When the jet is applied at a high speed, the pressure drops and a vacuum is generated. There is a structure called a nozzle, and these differences in shape and size determine the degree of vacuum, inhalation volume, and air consumption. On the contrary, Supplementary Fig. 2 shows a measuring system for measuring suction pressure. The air supply pressure to the ejector was adjusted to $0.3 \mathrm{MPa}$ or 0.4 MPa. The suction flow rate (F) was adjusted to an arbitrary value by the flow adjustment knob (FA). Next, the valve (V) was gradually closed from the fully opened state, and $\mathrm{F}$ was lowered. The relationship between the suction pressure $(\mathrm{P})$ and $\mathrm{F}$ was measured by a U-shaped manometer and a mass flow meter (TM-2000, TOKYO KEISO CO., LTD., Tokyo, Japan). The measurement results were shown in Supplementary Table 1. Thus, the suction pressure of volatile anesthetic by a scavenging system was observed.

Acknowledgements I thank Setsuya Murata, CENTRAL UNI Co., Ltd., Tokyo, Japan, for providing assistance.

\section{Compliance with ethical standards}

Conflict of interest All authors declare that they have no conflict of interest.

\section{References}

1. Tamura T, Mori A, Nishiwaki K. A drainage system to decrease volatile anesthetic leakage for the several types of oxygenators during cardiopulmonary bypass. J Cardiothorac Vasc Anesth. 2019. https://doi.org/10.1053/j.jvca.2019.05.022 (in press)

Publisher's Note Springer Nature remains neutral with regard to jurisdictional claims in published maps and institutional affiliations.
Electronic supplementary material The online version of this article (https://doi.org/10.1007/s00540-019-02658-w) contains supplementary material, which is available to authorized users.

Takahiro Tamura

takahiro@med.nagoya-u.ac.jp

1

\footnotetext{
Department of Anesthesiology, Nagoya University

Graduate School of Medicine, 65 Tsurumai-cho, Showa-Ku,

Nagoya 466-8550, Japan
} 